\title{
Communication difficulties during 999 ambulance calls: observational study
}

\author{
J Higgins, S Wilson, P Bridge, M W Cooke
}

One of the key roles of ambulance call receivers is to obtain accurate information concerning the location of the patient and their complaint. The automatic tracing of calls to their source can accurately determine the location of most patients. Obtaining information on the patient's condition, however, depends on effective communication between the call maker and the call receiver. Ambulance services in the United Kingdom now use priority dispatch systems to categorise calls according to the level of urgency for medical treatment and to provide first aid advice (for example, cardiopulmonary resuscitation). ${ }^{12}$ The safety and effectiveness of priority dispatch has been assessed ${ }^{3}$; however, whether call receivers are able to procure accurate and reliable information has not been established. This study aimed to determine the nature and extent of communication problems encountered during 999 calls.

\section{Participants, methods, and results}

The study population comprised 999 calls received by an urban (West Midlands Ambulance Service) and a rural (Derbyshire Ambulance Service) ambulance service. A stratified systematic sample of the calls received over one week (early December 1998) was selected $(\mathrm{n}=1830)$. During this time, the West Midlands Ambulance Service received approximately 830 calls per day and the Derbyshire Ambulance Service received approximately 240 calls per day. An assessor listened to tape recorded calls to determine the caller's identity (for example, husband), location in relation to the patient, type of telephone, and communication difficulties. Cases were excluded if recording quality was very poor.

The method was piloted. ${ }^{4}$ A conversation was noted as having communication difficulties if the call receiver had to repeat the question, the caller gave an inappropriate response more than once, or misunderstanding occurred between caller and call receiver.

We used univariate analysis to assess the characteristics of callers and compare the two ambulance services, and stepwise discriminant analysis to establish the factors associated with communication problems.

Of 1830 calls, $482(26.3 \%)$ were associated with a communication problem that may delay ambulance dispatch or prevent delivery of first aid advice (table). Fewer problems were observed in Derbyshire than in the West Midlands.

The most common reason for communication problems occurring was the emotional state of the caller $(161 / 482,33.4 \%)$. Almost 10\% (45/482) of problems were related to the ambulance service call receiver missing information or failing to be understood by the caller. Communication problems were associated more with calls made from payphones or mobile phones $(110 / 221,49.8 \%)$ than with those made from land lines $(372 / 1609,23.1 \%)\left(\chi^{2}=71.2, \mathrm{df}=1 ; \mathrm{P}<0.001\right)$. The type of telephone (land line, payphone, mobile phone)
Emergency

Medicine Research Group, Centre for Primary Health Care Studies, School of Health and Social Studies, University of Warwick, Coventry CV4 7AL

J Higgins research fellow M W Cooke senior lecturer Emergency Medicine Research Group, Department of Primary Care and General Practice, University of Birmingham, Birmingham

B15 2TT

S Wilson senior research fellow $\mathrm{P}$ Bridge project officer Correspondence to: $\mathrm{S}$ Wilson s.wilson@bham. ac.uk

BMJ 2001;323:781-2

Communication difficulties associated with 999 calls to ambulance services. Values are numbers (percentages)

\begin{tabular}{|c|c|c|c|c|}
\hline & \multicolumn{3}{|c|}{ Calls to ambulance service } & \multirow[b]{2}{*}{$\begin{array}{c}\text { Significance (comparison } \\
\text { between sites) }\end{array}$} \\
\hline & $\begin{array}{c}\text { Derbyshire } \\
(n=600)\end{array}$ & $\begin{array}{l}\text { West Midlands } \\
(\mathrm{n}=1230)\end{array}$ & Total $(n=1830)$ & \\
\hline \multicolumn{5}{|l|}{ Problem associated with call } \\
\hline \multicolumn{5}{|l|}{ Caller: } \\
\hline Abusive & 0 & $2(0.2)$ & $2(0.1)$ & \\
\hline Breathless or ill, causing difficulty with explanations & $6(1.0)$ & $24(2.0)$ & $30(1.6)$ & \\
\hline Slow, vague, or deaf & $5(0.8)$ & $21(1.7)$ & $26(1.4)$ & \\
\hline Child & $1(0.2)$ & $4(0.3)$ & $5(0.3)$ & \\
\hline Emotional, excitable, upset, or speaking too quickly & $58(9.7)$ & $103(8.4)$ & $161(8.8)$ & \\
\hline Not understanding questions asked by call receiver & 0 & $4(0.3)$ & $4(0.2)$ & \\
\hline Not wanting to answer, or giving misleading information & 0 & $5(0.4)$ & $5(0.3)$ & \\
\hline Strong accent or dialect & $4(0.7)$ & $18(1.5)$ & $22(1.2)$ & \\
\hline Unclear or slurred speech, difficult to understand & $11(1.8)$ & $17(1.4)$ & $28(1.5)$ & \\
\hline Use of non-English language or poor command of English & $2(0.3)$ & $9(0.7)$ & $11(0.6)$ & \\
\hline \multicolumn{5}{|l|}{ Call receiver: } \\
\hline Speaking too fast or using phrases not understood by caller & $2(0.3)$ & $8(0.7)$ & $10(0.5)$ & \\
\hline Information from caller not absorbed & $10(1.7)$ & $25(2.0)$ & $35(1.9)$ & \\
\hline Difficulties with address or location* & $15(2.5)$ & $74(6.0)$ & $89(4.9)$ & \\
\hline Technical problems & $13(2.2)$ & $25(2.0)$ & $38(2.1)$ & \\
\hline Other & $5(0.8)$ & $11(0.9)$ & $16(0.9)$ & \\
\hline Number of communication problems & $132(22)$ & $350(28.5)$ & $482(26.3)$ & $\chi^{2}=8.66, d f=1 ; P=0.003$ \\
\hline \multicolumn{5}{|l|}{ Nature of call } \\
\hline Calls from patients, relatives, and friends & $292(48.7)$ & $669(54.4)$ & $961(52.5)$ & $\chi^{2}=5.3, d f=1 ; P=0.012$ \\
\hline Calls from health workers, carers, and police & $76(12.7)$ & $144(11.7)$ & $220(12.0)$ & $\chi^{2}=0.35, d f=1 ; P=0.3$ \\
\hline Calls from police and fire personnel & $26(4.3)$ & $83(6.8)$ & $109(6.0)$ & $\chi^{2}=4.2, d f=1, P=0.024$ \\
\hline Caller in close proximity to patient $†$ & $158(26.3)$ & $373(30.3)$ & $531(29.0)$ & $\chi^{2}=14.26, d f=1 ; P<0.001$ \\
\hline
\end{tabular}

${ }^{*}$ Caller did not know or could not spell the street name, or could only provide local landmarks or road number.

tCaller and patient are within hearing distance of each other. 
and communication problem were similar in Derbyshire and the West Midlands. Communication problems were less likely if the call was made by a health professional (for example, general practitioner, carer, nurse) rather than by someone else $(21 / 220,9.5 \% v$ $\left.461 / 1610,28.6 \% ; \chi^{2}=26.4 ; \mathrm{P}<0.001\right)$.

\section{Comment}

More than a quarter of emergency ambulance calls in this study had communication problems. Calls from mobile phones and payphones generated a higher rate of communication problems than those from land lines. Mobile phones, which are used increasingly, ${ }^{5}$ may help to reduce the time taken to notify the emergency services but the advantages of this must be weighed against the high rate of communication problems.

The occurrence of communication problems related to the emotional state of the caller highlights the need to train call receivers in dealing with people in emotional states. Use of medical/technical terms, some of which can cause considerable confusion (for example, "unconscious"), as well as talking too quickly and without clarity, have been identified as areas in which training of call receivers is needed.

Use of a standard land line, appropriate training of public service personnel, such as police and fire services, and further public education about the infor- mation required when making 999 calls may reduce the extent of the communication problem.

We thank all the control room staff at West Midlands Ambulance Service NHS Trust and Derbyshire Ambulance Service NHS Trust for their help in this study; Tracey Cooper, Steve Elliker, Claire Caswell, and the control room supervisors at both ambulance services for their assistance; and Mrs Teresa Allan for her statistical advice during the design and analysis phases of the project.

Contributors: $\mathrm{JH}$ undertook the analysis and compiled the first draft of the paper. SW designed the study, assisted in the analysis, gave statistical advice, and helped write the paper. $\mathrm{PB}$ was involved in the design of the study, undertook the call monitoring and data entry, and was involved in writing the paper. MWC designed the project, undertook the data validation, and had a substantial role in writing the paper. MWC and SW are joint guarantors of the paper.

Funding: Laerdal Foundation for Acute Medicine.

Competing interests: None declared.

1 Marsden AK. Getting the right ambulance to the right patient at the right time. Accid Emerg Nurs 1995;3:177-83.

2 McNaughton GW, Wyatt JP. Telephone guided CPR-it's good to talk! Pre-hosp Immed Care 1997;1:71-2.

3 Nicholl J, Coleman P, Parry G, Turner J, Dixon S. Emergency priority dispatch systems - a new era in the provision of ambulance services in the UK. Pre-hosp Immed Care 1996;3:71-5.

4 Cooke M, Wilson S. Are 999 callers in a position to give triage information and receive first aid advice? Pre-hosp Immed Care 1998;2:193-6.

5 Mobile Phones and Health Independent Expert Group on Mobile Phones-National Radiological Protection Board April 2000. www.iegmp.org.uk/IEGMPtxt.htm (accessed 18 August 2001)

(Accepted 21 May 2001)

\title{
Bad press for doctors: 21 year survey of three national newspapers
}

\author{
Nazia Y Ali, Thoebe Y S Lo, Victoria L Auvache, Peter D White
}

\section{St Bartholomew's and the Royal \\ London School of \\ Medicine and \\ Dentistry, Queen \\ Mary College, \\ London EC1A 7BE \\ Nazia Y Ali \\ medical student \\ Thoebe Y S Lo \\ medical student \\ Victoria L Auvache \\ medical student \\ Peter D White \\ senior lecturer \\ Correspondence to: P D White \\ p.d.white@mds. \\ qmw.ac.uk}

BMJ 2001;323:782-3
Many doctors believe that the media are portraying an increasingly negative image of doctors. ${ }^{12}$ Is this true? An Australian study found that negative stories were counterbalanced by positive ones, ${ }^{3}$ yet the newspaper coverage of the General Medical Council investigation into the Bristol paediatric cardiac surgeons was considered to be "emotive and largely hostile." We tested the hypotheses that newspapers have published more negative than positive stories about doctors, and that the ratio of negative to positive stories has increased.

\section{Participants, methods, and results}

We studied the Daily Telegraph, Guardian, and Daily Mail so that we could include both broadsheet and tabloid newspapers, and newspapers with different political views. We studied all articles published in November, from 1980 to 2000, choosing November to exclude both holidays and winter bed crises, while parliament was sitting.

We examined either microfilmed editions of the newspapers or electronic databases (when available). We searched for the text words doctor*, medic*, surgeon*, and Dr (having rejected words that did not appear in articles in a pilot study). We counted and coded relevant articles as positive, negative, or neutral towards doctors. We also counted the number of lines in each article, adjusting for the difference between electronic and microfilmed articles. Each newspaper was assessed by a different author of the study. Where coding was not clear cut the article was reviewed by two other authors and a consensus reached. The blindly rated intercoder reliability for 1999 was $72 \%$ for total agreement and $100 \%$ for agreement by two out of three raters. To minimise year by year variance we calculated three year rolling means (figure), but all statistical analyses used the original data, which were not normally distributed.

The numbers of neutral, negative, and positive articles increased significantly over time (Pearson's $r=0.49,0.52$, and 0.44 , respectively; $\mathrm{P}<0.001)$. The median ratio of negative to positive articles was 2.33 (interquartile range 1.50-3.75) for the whole period, with no change with time $(r=0.01, \mathrm{P}=0.96)$. The median ratio of negative to positive lines was 2.98 (1.44-6.89) for the whole period, with no significant change with time $(r=-0.04, \mathrm{P}=0.74)$. There was a trend over time for a smaller median ratio of negative to positive articles in the Daily Mail (1.75); ratios in the other papers were similar (Telegraph 2.7, Guardian 3.0) (Kruskall Wallis $\chi^{2}=5.07, \mathrm{df}=2, \mathrm{P}=0.08$ ), but there was no significant difference in the ratio of negative to positive lines $(\mathrm{P}=0.36)$ in all three newspapers. The peaks in negative reports in 1986-9 and 1996-2000 were related to several incidents being reported at the same time (for example, practising doctors with HIV infections, and allegations 